\title{
DISCURSOS MASCULINOS SOBRE PREVENÇÃO E PROMOÇÃO DA SAÚDE DO HOMEM
}

\author{
MALE DISCOURSES ON THE PREVENTION AND PROMOTION OF MEN'S HEALTH
}

DISCURSOS MASCULINOS SOBRE PREVENCIÓN Y PROMOCIÓN DE LA SALUD DEL HOMBRE

\author{
Matheus Luis Castelan Trilico \\ Gabriela Romano de Oliveira ${ }^{2}$ \\ Marinei Yuko Kijimura ${ }^{3}$ \\ Sueli Moreira Pirolo ${ }^{4}$
}

Resumo A promoção da saúde é uma proposta de política mundial, contemporânea na saúde pública, que traz a saúde em seu conceito amplo. A Política Nacional de Atenção à Saúde do Homem fundamenta-se na singularidade do gênero masculino. Este trabalho objetivou analisar o discurso dos homens sobre doença, prevenção, saúde e a necessidade de sua promoção. Pesquisa descritivo-exploratória com abordagem qualitativa, realizada com 57 homens, moradores adstritos a uma unidade da Estratégia Saúde da Família do município de Marília, estado de São Paulo, integrada ao Programa de Educação pelo Trabalho para a Saúde. Utilizou-se a técnica de discurso do sujeito coletivo, baseada nas perguntas 'o que você faz para manter sua saúde?' e 'o que você considera prejudicial para sua saúde?’ Nos resultados, os discursos analisados evidenciaram que a maioria dos homens não compreende em sua totalidade o sentido de saúde, doença e prevenção, além de se fundamentarem no dimensionamento biológico. A Política Nacional de Atenção à Saúde do Homem constitui importante estratégia de promoção da saúde, todavia ainda requer que profissionais e instituições de diversas áreas, além da saúde, sejam ágeis, criativos e capacitados para lidarem com tal singularidade e suas vulnerabilidades. Palavras-chave promoção da saúde; saúde do homem; atenção primária à saúde.

Abstract Promoting health is a global policy that has been proposed, is contemporary in public health, and addresses health from a broader viewpoint. The National Policy for Full Attention to Men's Health is based on male uniqueness. This study aimed to analyze men's discourse on disease prevention, on health, and on the need to promote it. Descriptive and exploratory qualitative research conducted with 57 men, residents assigned to a Family Health Strategy unit in the municipality of Marília, state of São Paulo, integrated with Education through Work for Health Program. The researchers used the discourse of the collective subject technique, which is based on the questions 'what do you do to maintain your health?' and 'what do you consider harmful to your health?' In the results, the discourses analyzed showed that most men do not fully understand the sense of health or disease and prevention, besides the fact that they base themselves on biological scaling. The National Policy for Full Attention to Men's Health is an important health promotion strategy; however, it still requires professionals and institutions from different areas, over and beyond health, to be agile, creative, and qualified to deal with such uniqueness and vulnerabilities.

Keywords promotion of health; human health; primary health care. 


\section{Introdução}

A promoção da saúde é uma proposta de política mundial, contemporânea na saúde pública e disseminada pela Organização Mundial da Saúde (OMS) a partir de 1984. Aprovada na Carta de Ottawa (Brasil, 2002), traz a saúde em seu conceito amplo, relacionando-a com qualidade de vida decorrente de processos complexos interligados a fatores como alimentação, justiça social, ecossistema, renda e educação. Também trabalha com o princípio de autonomia dos indivíduos e das comunidades, reforçando assim o planejamento e o poder local (Buss, 2003).

Nesse mesmo sentido, a Declaração de Alma-Ata, em 1978 (Brasil, 2002), estabelece a proposta da 'atenção primária à saúde' e amplia a visão do cuidado à saúde: sai da visão hierárquica do conhecimento especializado, incentiva o envolvimento da população e destaca os fatores necessários para propiciar a qualidade de vida e o direito ao bem-estar social. A atenção primária à saúde está estreitamente vinculada à 'promoção da saúde' e à prevenção de enfermidades, não abandonando as dimensões setorial e técnica e incluindo outras dimensões (Rabello, 2010).

No Brasil, a Estratégia Saúde da Família responde a essa ampliação do cuidado ao buscar a promoção da qualidade de vida e intervenção nos fatores que geram riscos, por meio de ações programáticas abrangentes e ações intersetoriais (Pinheiro e Mattos, 2001). Nessa perspectiva, entende-se importante a Política Nacional de Atenção à Saúde do Homem.

Criada em 2009, essa política procura incluir a masculinidade nas questões clínica e epidemiológica, oferecendo uma proposta singular de cuidado de promoção e recuperação da saúde (Rabello, 2010). Ela se fundamenta na idiossincrasia do gênero masculino - termo que, para o campo da pesquisa, refere-se apenas a áreas estruturais e ideológicas que envolvem relação entre os sexos, delimitando então um novo terreno (Scott, 1995). Gomes, Nascimento e Rebello (2008) evidenciam na literatura que os homens sofrem influência dessa representação da masculinidade, imprimindo a idealização de sucesso, poder e força.

Estudos comparativos entre homens e mulheres comprovam que os homens são mais vulneráveis às doenças, sobretudo às enfermidades graves e crônicas, e morrem mais precocemente que as mulheres (World Health Organization, 2013; Brasil, 2008). A despeito da maior vulnerabilidade e das altas taxas de morbimortalidade, os homens não buscam, como as mulheres, os serviços de atenção básica.

Segundo estatísticas do Ministério da Saúde (Brasil, 2008), o homem é mais vulnerável à violência, seja como autor, seja como vítima. A prevalência de dependentes de álcool também é maior para o sexo masculino: 19,5\% dos homens são dependentes de álcool, contra 6,9\% das mulheres. Em relação ao 
tabagismo, os homens usam cigarros também com maior frequência do que as mulheres, o que acarreta maior vulnerabilidade a doenças cardiovasculares, cânceres, doenças pulmonares obstrutivas crônicas, doenças bucais e outras.

A masculinidade hegemônica seria aquela ligada à legitimidade do patriarcado, que garante a dominação dos homens e a subordinação das mulheres (Gomes, 2008). Ela não diz respeito a um estilo de vida, mas a configurações que formam as relações de gênero. Novos grupos podem desafiar antigas soluções e construir uma nova hegemonia. Hoje, essa demonstração de força, controle e não vulnerabilidade cede espaço, tirando do homem moderno toda essa supremacia (Costa, 2003).

No bojo dessas representações de masculinidade, busca-se o subjetivo contido na discussão de masculinidade e saúde e a consequente importância para tal, quando atribuída às políticas específicas de saúde pública voltada para o gênero masculino. Torna-se, então, necessário compreender suas representações no contexto do diálogo relacional ao gênero masculino, visando à promoção de saúde articulada ao princípio de autonomia dos indivíduos.

\section{Compreensão de conceitos de saúde}

A pesquisa 5 foi realizada na Unidade de Saúde da Família (USF) Jardim América IV, em Marília, São Paulo. Na área de abrangência desta USF, há 2.018 moradores e 705 famílias cadastradas. A escolha dessa unidade ocorreu em razão de ser o local de trabalho do preceptor envolvido com o Projeto Saúde do Homem financiado pelo Programa de Educação pelo Trabalho para a Saúde (Brasil, 2010).

Essa investigação se insere na pesquisa do tipo descritivo e exploratório, com abordagem qualitativa, modalidade que permite observar as diferentes perspectivas do objeto, sua singularidade e subjetividade (Flick, 2004). O objetivo foi o de compreender melhor os conceitos de saúde, doença, prevenção dos homens moradores na área de abrangência de uma USF, por meio da análise de seus discursos.

A população masculina existente é de 608 homens (30\% da população geral) entre 20 e 65 anos, os quais foram convidados a comparecer na USF para dialogar a respeito da sua saúde, em dias previamente agendados, nos períodos noturno e diurno. Para a composição da amostra, elegemos como critérios de inclusão: ter emprego e moradia fixos e estar dentro da faixa etária já mencionada da população masculina. Depois de contabilizadas as exclusões e as recusas, participaram da pesquisa 57 homens, constituindo uma amostra não probabilística por conveniência.

Para a coleta de dados foi elaborado um roteiro de entrevista semiestruturada, com perguntas abertas referentes à identificação, concepção sobre 
saúde e práticas para sua manutenção. Segundo Flick (2004), essa técnica permite que o informante expresse livremente sua opinião sobre o assunto referido pelo pesquisador, pois o roteiro consiste em instrumento orientador, um facilitador da comunicação. O teste-piloto foi realizado para adequação de termos.

A técnica do Discurso do Sujeito Coletivo (DSC), que é uma modalidade de apresentação dos resultados de pesquisa qualitativa (Lefèvre e Lefèvre, 2003), foi utilizada para organizar e tabular os depoimentos verbais. A DSC consiste em extrair dos depoimentos:

A ideia central (IC): nome ou expressão linguística que revela e descreve da maneira mais sintética, precisa e fidedigna possível o sentido das afirmações específicas presentes em cada um dos discursos analisados. Não é uma interpretação, mas uma descrição do sentido de um depoimento ou de um conjunto de depoimentos.

As expressões-chave: pedaços, trechos ou transcrições literais do discurso, que devem ser sublinhados, iluminados, coloridos pelo pesquisador e que revelam a essência do depoimento ou a base que o gerou. A esta base denomina-se ancoragem.

O DSC: como figura metodológica, retrata um discurso-síntese, redigido na primeira pessoa do singular e elaborado com base em ideias centrais, expressões-chave e ancoragens, compondo a soma das ideias e da base contextual do discurso elaborado.

A análise dos depoimentos permitiu identificar três categorias de DSCs com repertório de linguagem coerente com a questão proposta em dado momento histórico e segundo a formação sociocultural desses homens, que em forma discursiva sinalizam pensamentos e valores associados ao conceito de saúde, doença e prevenção, além de uma categoria com vocabulário restrito ou mesmo ausência deste. O conteúdo de cada uma dessas quatro categorias é único e o diferencia das demais, podendo ser mais bem exemplificado da seguinte forma:

Biológica: representa o biológico por meio de discursos que compreendem o cuidado com a saúde física relacionado com a homeostase do corpo, excluindo-se características psicológicas.

Psicológica: representa o psicológico, usando-se argumentos que mostram influências no corpo por meio da saúde mental.

Social: composto por influências das informações advindas do ambiente de vivência do indivíduo na sociedade e da sua compreensão de saúde com uma conotação que ultrapassa a dimensão psicológica; a biológica se apresenta como uma repercussão social. 
Não se aplica: composta por depoimentos com vocabulário restrito e homens que não quiseram responder à pergunta ou responderam a ela de forma incoerente com a questão proposta. Assim, esses depoimentos tornaram-se impossibilitados de ser agrupados nas demais categorias.

O projeto foi aprovado no Comitê de Ética em Pesquisa da Faculdade de Medicina de Marília, sob protocolo n. 1.214/10. Previamente, os participantes receberam e assinaram termo com esclarecimentos a respeito do objetivo e método, da garantia do sigilo e anonimato, da livre opção de participar ou cancelar sua permissão sem penalidade alguma.

\section{Construção e análise dos discursos do sujeito coletivo}

Os dados obtidos, além da construção e análise dos DSCs, possibilitaram elucidar o perfil do grupo. Para tanto, as principais variáveis utilizadas foram a idade, o grau de escolaridade e a renda média dos participantes.

Nesta pesquisa, $28,07 \%$ dos homens têm entre 38 e 46 anos; $22,80 \%$ corresponderam à faixa etária de 29 a 37 anos e outros $22,80 \%$ entre 47 a 55 anos; $19,30 \%$ dos homens estão na faixa entre 20 e 28 anos; e 7,02\% têm idade superior a 55 anos.

No que se refere à escolaridade, verifica-se o predomínio de homens com segundo grau completo $(36,9 \%)$, seguidos daqueles com o primeiro grau completo $(21 \%)$ e primeiro grau incompleto (14\%).

Considerando o salário mínimo de R \$ 545,00 (à época da pesquisa), a população em estudo agrupa-se quanto à renda da seguinte forma: 40,30\% dos homens recebem até três salários mínimos; 35,07\% recebem entre três e seis salários mínimos; e 7,01\% recebem mais de seis salários mínimos. De acordo com os dados colhidos, 17,54\% não quiseram declarar sua renda.

Os depoimentos permitiram identificar qualitativamente as práticas para manutenção e prejuízo da saúde. Para tanto, utilizou-se o agrupamento de ICs distribuindo-as percentualmente de acordo com seu enquadramento nas categorias biológica (A), psicológica (B), social (C) e não se aplica (D).

A questão 'O que você faz para manter sua saúde?' gerou discursos passíveis de serem alocados nas quatro categorias do DSC. O Quadro 1 mostra o percentual de homens e o DSC alocado. 
Quadro 1

\begin{tabular}{|c|c|c|}
\hline \multicolumn{3}{|c|}{ Pergunta 1: O que você faz para manter sua saúde? } \\
\hline Categoria & $\%$ & DSC desta categoria \\
\hline A & $66,6 \%$ & $\begin{array}{l}\text { "Procuro uma alimentação equilibrada: me alimento de comidas mais leves (verduras e } \\
\text { frutas), evito churrasco, faço regime. Não bebo álcool, não fumo, tento não ter uma vida } \\
\text { sedentária, fazendo exercícios, trabalhando. Cuido da minha higiene, faço prevenção e } \\
\text { controle da pressão arterial, evito extravagâncias." }\end{array}$ \\
\hline B & $8,8 \%$ & "Preocupo-me em não ficar nervoso, em esquecer os problemas e em dormir cedo." \\
\hline$C$ & $5,3 \%$ & "Procuro dormir bem, não fumar, não beber, seguir a 'orientação' médica, cuidar-me." \\
\hline D & $19,3 \%$ & $\begin{array}{l}\text { Esta é uma categoria composta por depoimentos sem repertório de linguagem e, } \\
\text { portanto, incapaz de formar um DSC. }\end{array}$ \\
\hline
\end{tabular}

Fonte: Os autores.

Nota: Categorias - biológica (A); psicológica (B); social (C); e não se aplica (D).

O Quadro 1 evidencia que a maioria desses homens $(66,6 \%)$ tem seu DSC baseado em componentes biológicos, pertencendo à categoria A. Deles, $8,8 \%$ formam um DSC de caráter psicológico, enquadrando-se na categoria B, e em apenas $5,3 \%$ dos discursos há predomínio de componentes sociais pertencentes à categoria C. Já 19,3\% dos discursos não possuíam repertório de linguagem compatível com a pergunta em questão e, por isso, foram categorizados em D.

O Quadro 2 registra as três principais ideias centrais na construção de cada DSC e suas respectivas prevalências em relação às demais, distribuídas por tipo de categoria. 
Quadro 2

\begin{tabular}{|c|c|c|c|c|c|c|c|}
\hline \multicolumn{2}{|c|}{ Categoria A } & \multicolumn{2}{|c|}{ Categoria B } & \multicolumn{2}{|c|}{ Categoria C } & \multicolumn{2}{|c|}{ Categoria D } \\
\hline ICs & $\%$ & ICs & $\%$ & ICs & $\%$ & $\mathrm{ICs}$ & $\%$ \\
\hline $\begin{array}{l}\text { Realizar } \\
\text { exercício } \\
\text { físico }\end{array}$ & $45 \%$ & $\begin{array}{c}\text { Não se } \\
\text { preocupar }\end{array}$ & $40 \%$ & $\begin{array}{c}\text { Não seguir a } \\
\text { orientação } \\
\text { médica }\end{array}$ & $67 \%$ & - & - \\
\hline $\begin{array}{c}\text { Ter } \\
\text { alimentação } \\
\text { saudável }\end{array}$ & $16 \%$ & $\begin{array}{l}\text { Não se } \\
\text { estressar }\end{array}$ & $20 \%$ & $\begin{array}{c}\text { Não } \\
\text { consumir } \\
\text { remédio com } \\
\text { álcool }\end{array}$ & $33 \%$ & - & - \\
\hline $\begin{array}{l}\text { Não ingerir } \\
\text { bebida } \\
\text { alcoólica }\end{array}$ & $13 \%$ & $\begin{array}{c}\text { Ter saúde } \\
\text { mental }\end{array}$ & $20 \%$ & - & - & - & - \\
\hline
\end{tabular}

Fonte: Os autores.

Nota: Categorias - biológica (A); psicológica (B); social (C); e não se aplica (D).

As principais ICs que levam à formação do DSC para a categoria A são 'realizar exercício físico' (45\%), 'ter alimentação saudável' (16\%) e 'não ingerir bebida alcoólica' (13\%). Já para o DSC da categoria B, tem-se: 'não se preocupar' (40\%), 'não se estressar' $(20 \%)$ e 'ter saúde mental' $(20 \%)$. O DSC inserido na categoria C é composto basicamente por duas ideias centrais - 'não seguir a orientação médica' $(67 \%)$ e 'não consumir remédio com álcool' (33\%). Já a categoria D, por não possuir um DSC, é desprovida de ideias centrais relacionadas à pergunta em questão.

A questão 'O que você considera prejudicial para sua saúde?' gerou discursos passíveis de serem alocados em três categorias do DSC. O Quadro 3 mostra o percentual de homens e seu DSC conforme a categoria. 
Quadro 3

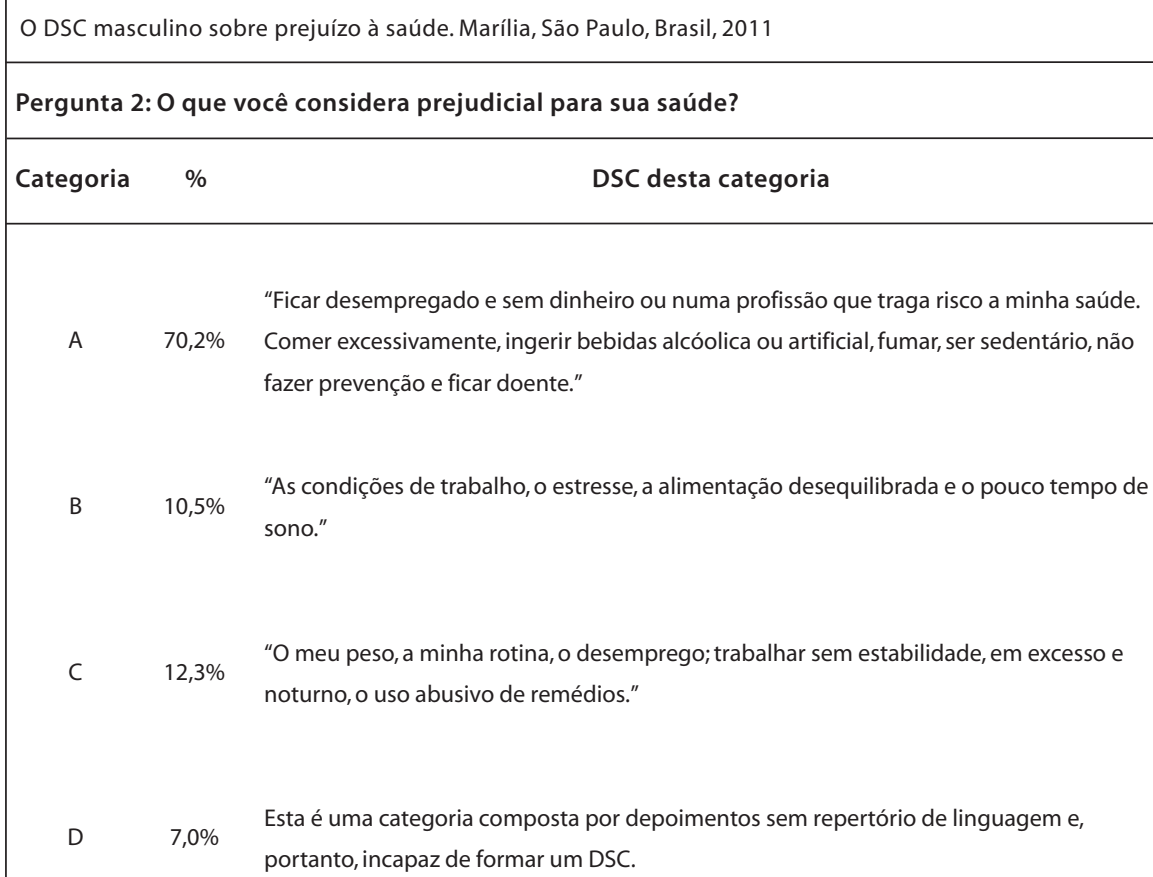

Fonte: Os autores.

Nota: Categorias - biológica (A); psicológica (B); social (C); e não se aplica (D).

De acordo com o Quadro 3, 70,2\% dos discursos têm componentes biológicos em sua formação, enquadrando-se na categoria A; 10,5\% baseiam-se em elementos psicológicos, incluindo-se na categoria $\mathrm{B} ; 12,3 \%$ compõem-se de características sociais, agrupando-se na categoria C. Apenas $7 \%$ dos discursos não possuíam repertório de linguagem compatível com a questão e, por isso, foram categorizados em D.

O Quadro 4 dispõe as três principais ideias centrais na construção de cada DSC e suas respectivas prevalências em relação às demais, distribuídas por tipo de categoria. 
Quadro 4

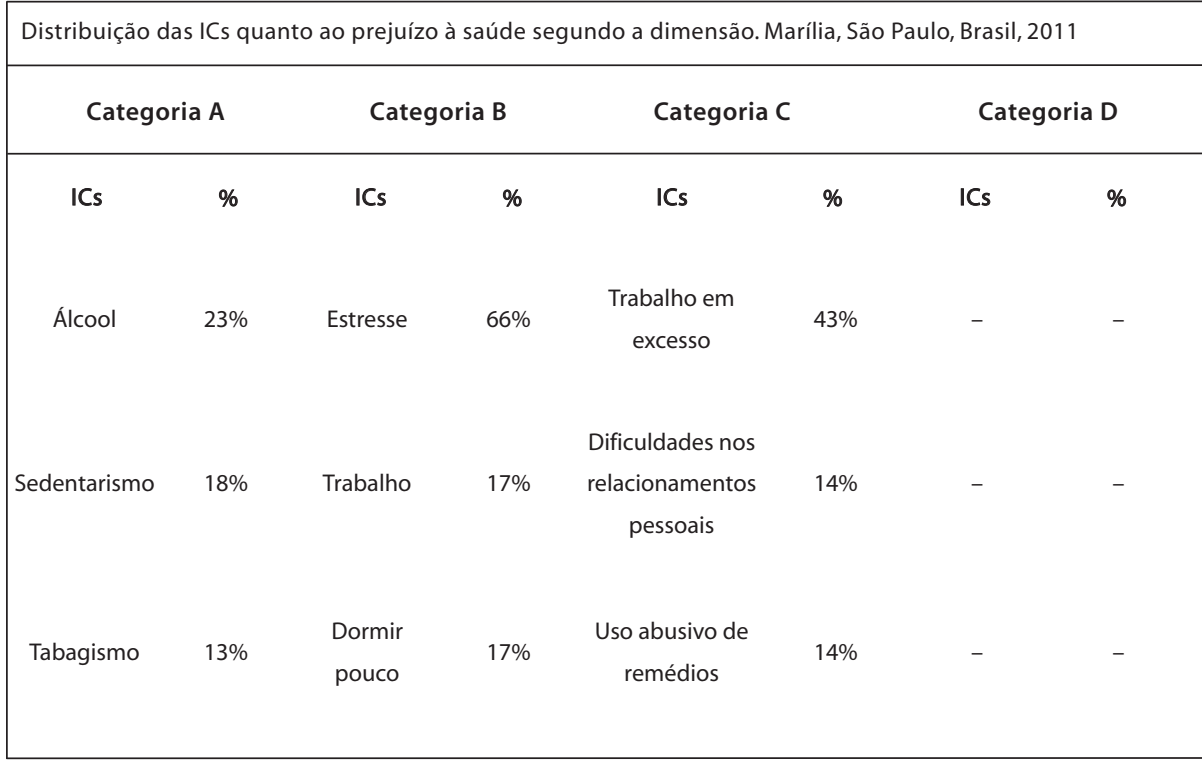

Fonte: Os autores.

Nota: Categorias - biológica (A); psicológica (B); social (C); e não se aplica (D).

As principais ICs que levam à formação do DSC para a categoria A são 'álcool' (23\%), 'sedentarismo' (18\%) e 'tabagismo' (13\%). Já para o DSC da categoria B, tem-se: 'estresse' (66\%), 'trabalho' (17\%) e 'dormir pouco' $(17 \%)$. O DSC da categoria C é composto pelas ideias centrais 'trabalho em excesso' (43\%), 'dificuldades nos relacionamentos pessoais' (14\%) e 'uso abusivo de remédios' (14\%). Já a categoria D, por não possuir um DSC, é desprovida de ideias centrais relacionadas à pergunta em questão.

\section{Álcool, sedentarismo e tabagismo: agressão à saúde}

Com base nos resultados apresentados, pode-se caracterizar essa população masculina como predominantemente adulta, com proventos de até três salários mínimos e segundo grau de escolaridade completo.

Quando esses homens são questionados sobre o que fazem para manter sua saúde, a maioria fundamenta suas respostas em conceitos biológicos, compostos principalmente pela ideia de que a manutenção da saúde se baseia na realização de exercícios físicos, em uma alimentação saudável e na não ingesta de bebidas alcoólicas. O mesmo se repete quando indagados sobre o que consideram prejudicial - para eles, álcool, sedentarismo e tabagismo formam a tríade agressora à saúde. 
Analisando os DSCs de ambas as perguntas para a categoria A, nota-se que 'regime alimentar' mostra um conceito de que perder peso enquadra-se em hábitos alimentares saudáveis, explicitados segundo a imagem corporal. A atividade laboral também é vista como uma questão essencial para a manutenção da saúde, considerada atividade para o corpo e fonte de renda. Assim, o desemprego torna-se um prejuízo a ela pelo impedimento de se ter condição financeira suficiente para 'comprar' uma vida mais saudável - por exemplo, lazer e uma boa alimentação. Ainda nessa categoria, esses homens consideram que um dos meios de se manter saudável é a prática da prevenção, que se baseia na concepção de risco ou de probabilidade de se tornar doente, conforme a vulnerabilidade dos indivíduos.

O conceito de vulnerabilidade usado por Mann, Tarantola e Netter (1993) busca avaliar a suscetibilidade de indivíduos ou grupos a um determinado agravo à saúde. Pode ser dividido em três dimensões: a individual, a programática e a social. Para Ayres e colaboradores (2003), o termo vulnerabilidade relaciona-se à chance de exposição das pessoas ao adoecimento como resultante de um conjunto de aspectos que, ainda que se refiram imediatamente ao indivíduo, o recolocam na perspectiva de dupla-face, ou seja, o indivíduo e sua relação com o coletivo.

Assim, a prevenção e a promoção da saúde deveriam considerar o conhecimento pessoal acerca do agravo e a existência de comportamentos que oportunizam sua ocorrência; o acesso aos serviços de saúde, sua organização, o vínculo e o acolhimento com os usuários e as ações em sua área de abrangência; e a dimensão social do adoecimento por meio de indicadores capazes de revelar o perfil da população no âmbito almejado.

Esses homens mostram uma visão de doença como oposição à saúde, um conceito enraizado na sociedade ocidental e na prática médica (Backes et al., 2009). No entanto, essa contraposição saúde-doença pode ser problemática, uma vez que não existe saúde como sinônimo de cura definitiva, pois sempre será possível que se encontre alguma espécie de desequilíbrio no corpo humano. Felizmente, nas últimas décadas, a saúde passa a ser relacionada com as noções de bem-estar e satisfação pessoal, e não a um oposto ao negativo representado pela doença (Rabello, 2010).

A definição de saúde para a OMS é a de "um estado de completo bem-estar físico, mental e social e não meramente a ausência de doença e debilitamento" (Scliar, p. 37, 2007). Todavia, ela pode ser utópica e contraditória, visto que hoje é possível viver saudável mesmo na ausência de um 'completo bem-estar' (Menicucci, 2009). O conceito ampliado de saúde vai ainda além e mostra que ela é principalmente resultado das formas de organização social (Batistella, 2008).

Podemos dizer que a saúde é uma categoria resultante da interação do homem, ser biológico, psicológico, social e espiritual, com a família, com o 
coletivo de trabalho e com a comunidade. Essa é uma ideia visível nos DSCs dos homens entrevistados, ainda que não majoritariamente.

A minoria desses homens baseia suas respostas em fatores psicossociais e faz deles pontos-chave para a manutenção da saúde, conforme mostra o quadro 2 - suas ICs 'não biológicas' predominantes resumem-se em 'não se preocupar', 'não se estressar', 'ter saúde mental', além de 'seguir o tratamento médico' e 'não consumir remédio com álcool'. Todos esses conceitos demonstram que, mesmo inferiores a $40 \%$, uma parcela dessa população aparenta compreender o conceito de saúde em seu aspecto amplo, tendo como partes desse alicerce, além do biológico, o social e o psicológico.

No entanto, para se chegar a tal entendimento, urge saber que as ICs apresentadas são reflexos do ambiente social em que esses homens estão inseridos e das informações que lhes são repassadas. Assim, eles consideram, por influência social, que seguir uma orientação médica e não ingerir quaisquer fármacos com bebidas alcoólicas são essenciais à saúde.

Tal atitude mais uma vez remete ao paradigma da 'promoção da saúde' e à importância desta na compreensão da saúde como resultado de ações multidimensionais, do esforço da comunidade organizada para sua manutenção e melhoramento (Buss, 2003). A 'promoção da saúde' afeta a população em seu conjunto no contexto de sua vida diária, pretende influir nos determinantes causais ou nas causas das doenças, combina métodos ou enfoques distintos, porém específicos da população. Os profissionais da saúde, particularmente no campo da atenção primária, desempenham suma importância em sua defesa e facilitação (Rabello, 2010).

A 'promoção da saúde' relaciona-se mais fortemente aos múltiplos aspectos de modos de vida, por meio de fatores protetores para uma vida saudável, transcendendo mudanças de hábitos individuais, como o uso do álcool e do cigarro, a alimentação saudável, os exercícios e o controle do estresse, entre outros - além de sua relação com os processos da realidade social (Sícoli e Nascimento, 2003). Ela propõe que se aceite a saúde como um dos objetivos sociais fundamentais dos governos, um dos componentes-chave do bem público, e que se busquem formas de propiciar aos cidadãos vidas produtivas, social e economicamente, sendo redefinida para "processo de capacitação da comunidade para atuar na melhoria da sua qualidade de vida e saúde, incluindo uma maior participação no controle desse processo" (Sícoli e Nascimento, p. 108, 2003). A proposta considera ainda como condições e pré-requisitos para a promoção da saúde a paz, a educação, a habitação, a alimentação, a renda, um ecossistema estável, recursos sustentáveis, justiça social e equidade (Rabello, 2010).

Essa promoção, portanto, insere-se no debate de transformação social e no desenho de políticas e ações sociais integrais que possibilitem alternativas 
de desenvolvimento, o que enfatiza a importância do Estado e da sociedade civil na consecução de suas propostas.

\section{Considerações finais}

A técnica do DSC para uma abordagem qualitativa evidenciou a dificuldade em se compreender o subjetivo, mesmo com o uso de ferramentas específicas. Por melhor que estas sejam, um diagnóstico de qualidade continua centrado na capacidade de compreensão do examinador e na sua tentativa de imparcialidade. Apesar da existência desses obstáculos, os resultados comprovam a necessidade de um olhar voltado ao público masculino e que vise ampliar seu entendimento sobre saúde, doença, prevenção e "promoção' por meio de suas práticas, principalmente na atenção primária.

O estudo demonstra que há necessidade de se fomentarem pesquisas para melhor compreender as reais necessidades desse grupo com relação aos dados expostos, suas expectativas, bem como de eleger formas mais eficazes de intervenção a fim de uma mudança eficaz e segura. Essa conclusão viabiliza modificar as realidades das instituições de saúde e implementar novas políticas.

A promoção da saúde precisa, também, do apoio de outros setores da sociedade - como as escolas, que, por serem fontes de aprendizado e formadoras de opinião, podem colaborar com a educação sobre saúde. Assim, poderemos fomentar o entendimento sobre a importância desse assunto, buscando uma saúde coletiva de excelência e menos dispendiosa à nação.

\section{Colaboradores}

O primeiro autor concebeu o estudo em termos teóricos e metodológicos; coletou, analisou e processou os dados, elaborou a discussão dos resultados e redigiu o texto. O segundo coletou e analisou os dados, participou da orientação metodológica, da versão e da revisão finais do texto. O terceiro e o quarto autores participaram da orientação teórica e metodológica, da análise dos dados, da discussão dos resultados e da revisão do texto final do artigo. 
Resumen La promoción de la salud es una propuesta de la política mundial, contemporánea en la salud pública, que abarca la salud en su concepto más amplio. La Política Nacional de Atención a la Salud del Hombre se basa en la singularidad del género masculino. Este estudio tuvo como objetivo analizar el discurso de los hombres sobre enfermedades, prevención, salud y la necesidad de su promoción. Una investigación descriptiva y exploratoria con criterio cualitativo, fue realizada con 57 hombres, residentes asignados a una unidad del municipio de la Estrategia Salud de la Familia del municipio de Marilia, estado de São Paulo, integrada al Programa de Educación por el Trabajo para la Salud. Se utilizó la técnica de discurso del sujeto colectivo, basada en las preguntas “¿Qué hace para mantener su salud?”, y “¿Qué considera perjudicial para su salud?” En los resultados, los discursos analizados mostraron que la mayoría de los hombres no comprenden en su totalidad el sentido de la salud, la enfermedad y la prevención, además de basarse en la dimensión biológica. La Política Nacional de Atención a la Salud del Hombre constituye una importante estrategia de promoción de la salud, sin embargo todavía requiere que profesionales e instituciones de diferentes campos, además de la salud, sean ágiles, creativos y capacitados para tratar con tal singularidad y sus vulnerabilidades.

Palabras clave promoción de la salud; salud del hombre; atención primaria de la salud.

\section{Notas}

1 Faculdade de Medicina de Marília, Marília, São Paulo, Brasil.

Graduando de Medicina na Faculdade de Medicina de Marília. Bolsista do Programa de Educação pelo Trabalho para a Saúde (PET-Saúde).

$<$ matheus.trilico@gmail.com>

Correspondência: Rua Doutor Assis Brasil, 303, Vila Angélica, CEP 15050-040, São José do Rio Preto, São Paulo, Brasil.

2 Faculdade de Medicina de Marília, Marília, São Paulo, Brasil. Graduada em Medicina pela Faculdade de Medicina de Marília.

<gabifamema@yahoo.com.br>

${ }^{3}$ Faculdade de Medicina de Marília, Marília, São Paulo, Brasil.

Graduada em Medicina pela Faculdade de Medicina de Marília.

$<$ mari_kijimura@hotmail.com>

4 Faculdade de Medicina de Marília, Departamento de Enfermagem, Marília, São Paulo, Brasil.

Doutora em Enfermagem pela Escola de Enfermagem de Ribeirão Preto da Universidade de São Paulo.

<pirolo@famema.br>

5 Artigo original, fruto da pesquisa intitulada "Saúde do homem na atenção primária", de autoria de Matheus L. C. Trilico, Gabriela R. de Oliveira, Mariney Y. Kijimura e Sueli M. Pirolo, financiada pelo Programa de Educação pelo Trabalho para a Saúde (PET-Saúde) e aprovada pelo Comitê de Ética em Pesquisa da Faculdade de Medicina de Marília, sob o protocolo n. 1.214/10. Não há conflito de interesses. 


\section{Referências}

AYRES, José R. de C. M. et al. O conceito de vulnerabilidade e as práticas de saúde: novas perspectivas e desafios. In: CZERESNIA, Dina (Org.). Promoção da saúde: conceitos, reflexões, tendências. Rio de Janeiro: Editora Fiocruz, 2003. p. 117-138.

BACKES, Marli T. S. et al. Conceitos de saúde e doença ao longo da história sob o olhar epidemiológico e antropológico. Revista de Enfermagem Uerj, Rio de Janeiro, v. 1, n. 17, p. 111-117, mar. 2009.

BATISTELlA, Carlos. O território e o processo saúde-doença. 2008. Disponível em: <www.epsjv.fiocruz.br/pdtsp/index.php? s_livro_id $=6 \&$ area_id $=2 \&$ autor_id $=\&$ capitulo_id=14\&sub_capitulo_id $=32 \&$ arquivo=ver_conteudo_2 $>$. Acesso em: jan. 2014.

BRASIL. Ministério da Saúde. As cartas de promoção à saúde. Brasília: Ministério da Saúde, 2002. Disponível em: <http://bvsms. saude.gov.br/bvs/publicacoes/cartas_ promocao.pdf>. Acesso em: 21/01/2015.

BRASIL. Ministério da Saúde. Politica Nacional de Atenção Integral à Saúde do Homem. Brasília: Ministério da Saúde, 2008. Disponível em: <http://portal.saude.gov.br/ portal/arquivos/pdf/politica_nacional_ homem.pdf>. Acesso em: 24 jun. 2012.

BRASIL. Ministério da Saúde, Ministério da Educação. Portaria interministerial n. 421/MS/MEC, de 3 de março de 2010. Institui, no âmbito dos Ministérios da Saúde e da Educação, o Programa de Educação pelo Trabalho para a Saúde-PET Saúde, destinado a fomentar a formação de grupos de aprendizagem tutorial em áreas estratégicas para o Sistema Único de Saúde (SUS). Diário Oficial da União, Brasília, DF, 5 mar. 2010. p. 53.

BUSS, Paulo M. Uma introdução ao conceito de promoção da saúde. In: CZERESNIA,
Dina; FREITAS, Carlos M. de. (Orgs.). Promoção da saúde: conceitos, reflexões, tendências. Rio de Janeiro: Editora Fiocruz, 2003. p. $15-38$.

COSTA, Rosely G. Saúde e masculinidade: reflexões de uma perspectiva de gênero. Revista Brasileira de Estudos de População, Rio de Janeiro, v. 20, n. 1, p. 79-92, 2003.

FLICK, Uwe. Uma introdução à pesquisa qualitativa. 2. ed. Porto Alegre: Bookman, 2004.

GOMES, Romeu. Sexualidade masculina, gênero e saúde. Rio de Janeiro: Editora Fiocruz, 2008.

GOMES, Romeu; NASCIMENTO, Elaine F.; REBELLO, Lúcia E. F. S. As representações da masculinidade e o ser homem. In: FAZENDO GÊNERO - CORPO, VIOLÊNCIA E PODER, 8, 2008, Florianópolis. Anais eletrônicos... Florianópolis: Universidade $\mathrm{Fe}$ deral de Santa Catarina, 2008. Disponível em: $<$ www.fazendogenero.ufsc.br/8/sts/ST56/ Gomes-Nascimento-Rebello_56.pdf $>$. Acesso em: 1 fev. 2014.

LEFÈVRE, Fernando; LEFÈVRE, Ana Maria C. O discurso do sujeito coletivo: um novo enfoque em pesquisa qualitativa (desdobramentos). Caxias do Sul: Editora da Universidade de Caxias do Sul (Educs), 2003.

MANN, Jonathan; TARANTOLA, Daniel J. M.; NETTER, Thomas W. (Orgs.). A Aids no mundo. Rio de Janeiro: Relume-Dumará, 1993.

MENICUCCI, Telma M. G. O Sistema Único de Saúde - 20 anos: balanço e perspectivas. Cadernos de Saúde Pública, Rio de Janeiro, v. 25, n. 7, p. 1.620-1.625, 2009.

PINHEIRO, Roseni; MATTOS, Ruben A. (Orgs.). Os sentidos da integralidade na atenção e no cuidado à saúde. Rio de Janeiro: IMS-Uerj/Abrasco, 2001. 
RABELLO, Lucíola S. Promoção da saúde: a construção social de um conceito em perspectiva comparada. 22. ed. Rio de Janeiro: Editora Fiocruz, 2010.

SCLIAR, Moacyr. História do conceito de saúde. Physis: Revista de Saúde Coletiva, Rio de Janeiro, v. 17, n. 1, p. 29-41, jan./abr. 2007.

SCOTT, Joan W. Gênero: uma categoria útil para análise histórica. Educação e Realidade, Porto Alegre, v. 20, n. 2, p. 71-99, jul./dez. 1995.
SÍCOLI, Juliana L.; NASCIMENTO, Paulo R. Promoção de saúde: concepções, princípios e operacionalização. Interface: Comunicação, Saúde, Educação, Botucatu, v. 7, n. 12, p. 101-122, fev. 2003.

WORLD HEALTH ORGANIZATION. World health statistics 2013. Geneva: World Health Organization, 2013. Disponível em: <www. who.int/gho/publications/world_health_ statistics/EN_WHS2013_Full.pdf>. Acesso em: 21 jan. 2015 .

Recebido em 22/11/2012

Aprovado em 31/03/2014 
